Bull. Mater. Sci., Vol. 6, No. 1, February 1984, pp. 17-20.

(C) Printed in India.

\title{
Mössbauer spectroscopy of titanium-substituted iron garnets
}

\author{
C M SRIVASTAVA, S N SHRINGI, B UMA MAHESHWAR RAO, \\ D BAHADUR* and OM PARAKASH** \\ Department of Physics, Indian Institute of Technology, Powai, Bombay 400076, India \\ *Advanced Centre for Materials Science, Indian Institute of Technology, Kanpur 208016, \\ India \\ **School of Materials Science and Technology, Banaras Hindu University, Varanasi 221005 , \\ India
}

\begin{abstract}
The Mössbauer spectroscopy of polycrystalline $\mathrm{Y}_{3-x} \mathrm{Ca}_{x} \mathrm{Fe}_{5-x} \mathrm{Ti}_{x} \mathrm{O}_{12}(x=02$, $0.5,0 \cdot 7)$ garnets has been studied at room temperature. The hyperfine fields both at the octahedral and tetrahedral sites decrease with increasing titanium content. The hyperfine fields both at $a$ and $d$-sites are linearly proportional to magnetization. The quadrupole splitting for a-site shows no dependence on Ti content while the quadrupole splitting for $d$-site increases slightly with $x$. The results are explained on the basis of lattice distortion due to Ti substitution on $a$-site.
\end{abstract}

Keywords. Garnet; hyperfine field; quadrupole splitting; iron garnet; Mössbauer spectra.

\section{Introduction}

The Mössbauer spectroscopy of polycrystalline $\mathrm{Y}_{3-x} \mathrm{Ca}_{x} \mathrm{Fe}_{5-x} \mathrm{Ti}_{x} \mathrm{O}_{12} \quad(x=0 \cdot 2,0 \cdot 5$, $0.7)$ garnets has been studied at room temperature. Yttrium iron garnet (YIG) and substituted yttrium iron garnets have been extensively studied because of their technical importance. Garnet structure allows a wide range of diamagnetic ion $\left(\mathrm{Al}^{3+}\right.$, $\left.\mathrm{Ga}^{3+}, \mathrm{Si}^{4+}, \mathrm{Sn}^{4+}, \mathrm{Ti}^{4^{+}}\right)$substitution on both octahedral $(a)$ and tetrahedral $(d)$ sublattices for the control of magnetization. For trivalent substitutions like $\mathrm{Al}^{3+}, \mathrm{Ga}^{3+}$ the diamagnetic ions distribute themselves between both $a$ and $d$-sites. In tetravalent substitutions like $\mathrm{Si}^{4+}, \mathrm{Sn}^{4+}, \mathrm{Ge}^{4+}, \mathrm{Ti}^{4+}$ it becomes necessary to substitute a divalent ion like $\mathrm{Ca}^{2+}$ for the charge compensation. These ions occupy the dodecahedral site replacing rare earth or yttrium ions. In $\mathrm{Ge}^{4+}$ and $\mathrm{Si}^{4+}$ substitution the diamagnetic ions have a strong preference for $d$-site, whereas for substitutions like $\mathrm{Sn}^{4+}$ and $\mathrm{Ti}^{4+}$ the diamagnetic ions occupy an $a$-site alone.

We have studied the effect of substitution of $\mathrm{Ti}^{4+}$ on magnetic properties and Mössbauer spectra of YIG. The compositions investigated are $\mathrm{Y}_{3-x} \mathrm{Ca}_{x} \mathrm{Fe}_{3-x} \mathrm{Ti}_{x} \mathrm{O}_{12}$ $(0<x<1)$. As mentioned earlier $\mathrm{Ti}$ is expected to occupy the $a$-site. Measurements of Curie temperature $\left(T_{c}\right)$ on these samples indicate that $T_{c}$ falls rapidly with $x(\mathrm{Om}$ Parakash and Bahadur 1982). The hyperfine fields $\left(H_{\mathrm{hf}}\right)$ at $\mathrm{Fe}^{3+}$ nuclei also show a similar fall. These results as well as the variation of quadrupole splitting (QS) with $\mathrm{Ti}$ substitution are discussed in this paper.

\section{Experimental}

The samples $\mathrm{Y}_{3-x} \mathrm{Ca}_{x} \mathrm{Fe}_{5-x} \mathrm{Ti}_{x} \mathrm{O}_{12}(0.2<x<1)$ were prepared using standard ceramic techniques from high purity $\mathrm{Y}_{2} \mathrm{O}_{3}, \mathrm{Fe}_{2} \mathrm{O}_{3}, \mathrm{Ti}_{2} \mathrm{O}_{3}$. The preparation of the 
samples and other magnetic measurements were reported recently (Om Parakash and Bahadur 1982). The $x$-ray diffraction data of the samples show the presence of single phase.

For the Mössbauer investigation the Mössbauer absorbers were made from fine powders. The data were collected by transducer drive in conjunction with 1024 multichannel analyser in constant acceleration mode.

\section{Results and discussion}

The Mössbauer spectra of $\mathrm{Y}_{3-x} \mathrm{Ca}_{x} \mathrm{Fe}_{5-x} \mathrm{Ti}_{x} \mathrm{O}_{12}(x=0 \cdot 2,0 \cdot 5,0 \cdot 7)$ obtained at $300 \mathrm{~K}$ are shown in figure 1. From the analysis of the spectra $H_{\mathrm{hf}}$ at $\mathrm{Fe}^{3+}$ nuclei on $a$ and $d$-sites and the corresponding Qs are obtained. These data are shown in figures 2 and 3. From figure 2 it can be observed that $H_{\mathrm{hf}}$ at $a$ and $d$-sites decreases with increase in titanium concentration $(x)$. The fall in $H_{\mathrm{hf}}$ is linearly proportional to the fall in magnetization. Figure 2 also gives the plots of variation of magnetization with $x$. The variation of $\mathrm{QS}$ is shown in figure 3 , and indicates that QS at $a$-site remains constant whereas $Q S$ at $d$-site shows a slight increase with increase in $x$. The substitution of Ti on

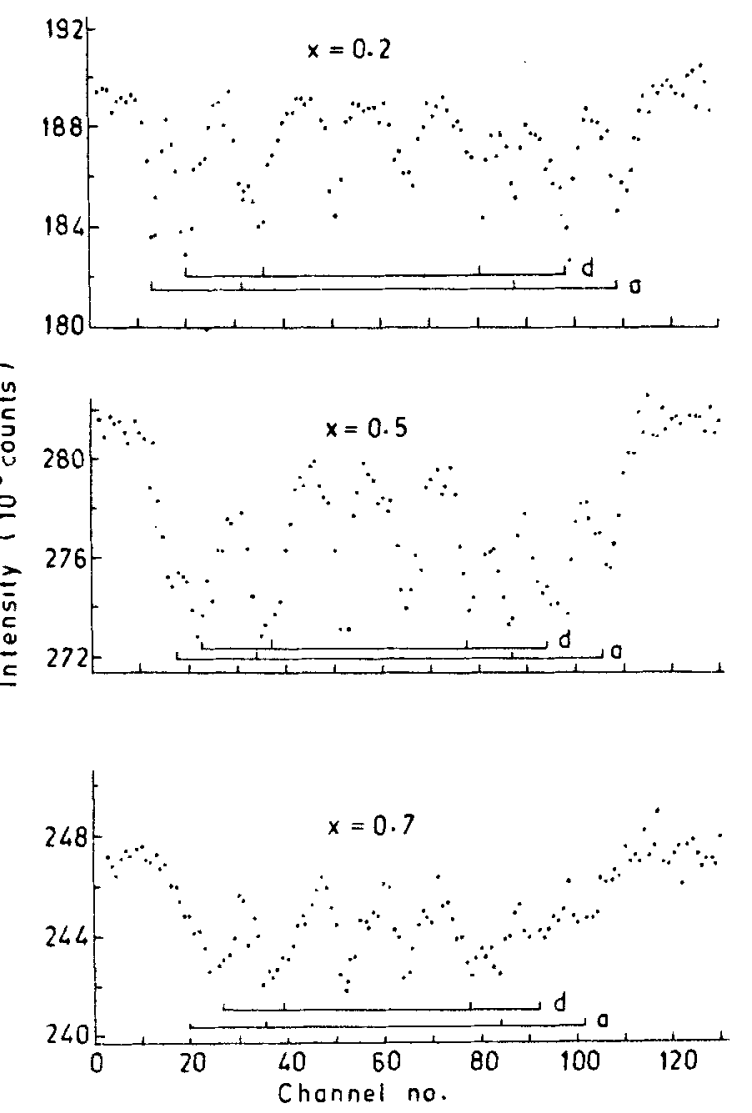

Figure 1. Mössbauer spectra of $\mathrm{Y}_{3-x} \mathrm{Ca}_{x} \mathrm{Fe}_{5-x} \mathrm{Ti}_{x} \mathrm{O}_{12}$ at $300 \mathrm{~K}$. (O velocity is at 58 channel; 1 channel $=0 \cdot 1591 \mathrm{~mm} / \mathrm{sec}$ ). 


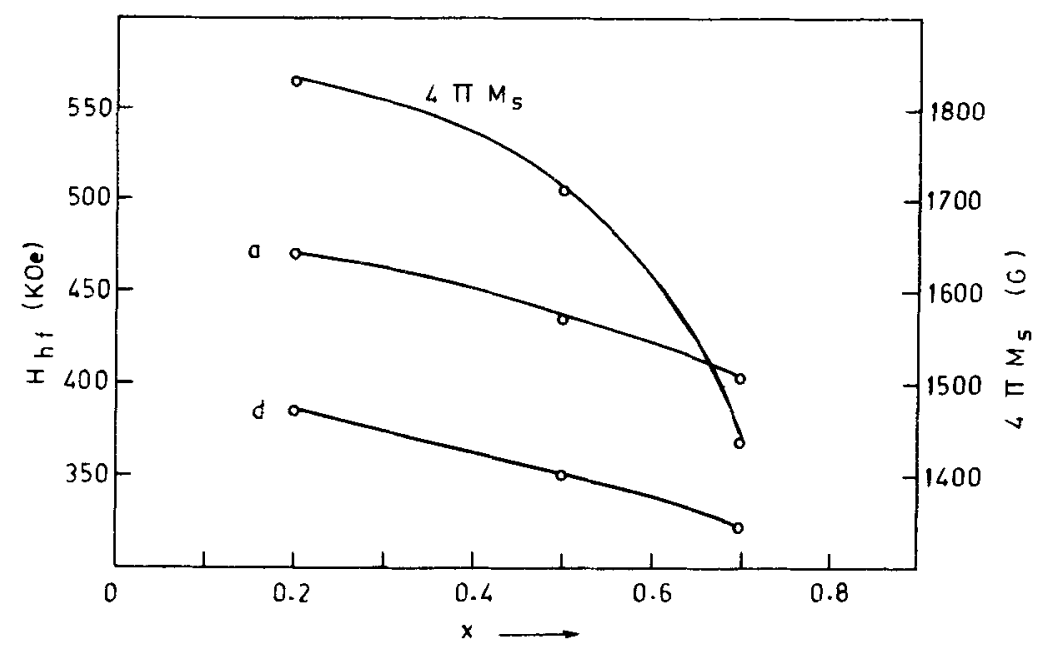

Figure 2. Variation of hyperfine field $H_{h f}$ for $a$ and $d$ sites and $4 \pi M_{s}$ in $\mathrm{Y}_{3-x} \mathrm{Ca}_{x} \mathrm{Fe}_{5-x} \mathrm{Ti}_{x} \mathrm{O}_{12}$ as a function of $x$.

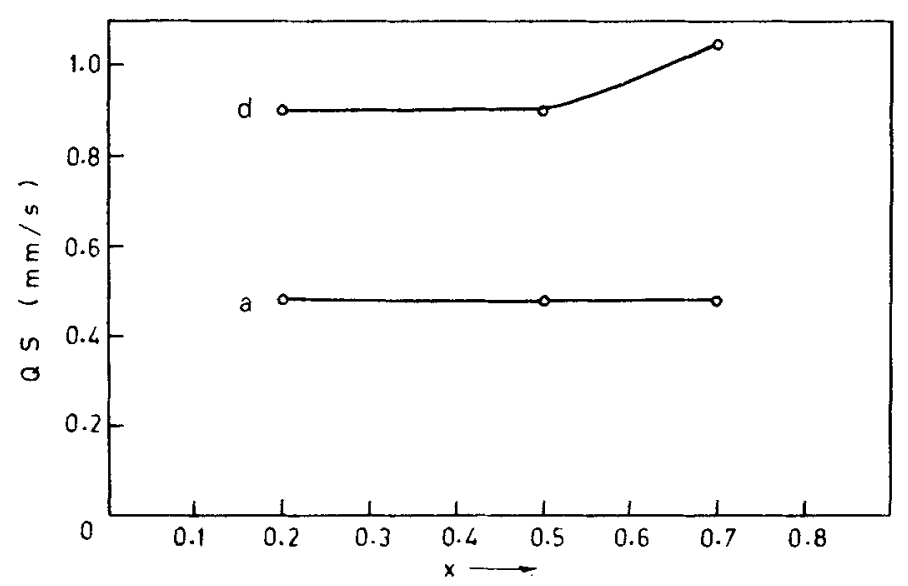

Figure 3. Quadrupole splitting for $a$ and $d$ sites in $\mathrm{Y}_{3-x} \mathrm{Ca}_{x} \mathrm{Fe}_{5-x} \mathrm{Ti}_{x} \mathrm{O}_{12}$ as a function of $x$.

the $a$-site creates an asymmetric displacement of the oxygen ions surrounding the $d$-site. This distortion of the oxygen tetrahedra on the $d$-site due to $\mathrm{Ti}^{4+}$ substitution on the $a$ site gives rise to the observed increase in Qs of the $d$-site. This observation is consistant with similar observations of $\mathrm{QS}$ in $\mathrm{Y}_{3-x} \mathrm{Ca}_{x} \mathrm{Fe}_{5-x} \mathrm{Si}_{x} \mathrm{O}_{12}$ (Lyubutin et al 1970) and $\mathrm{Y}_{3-x} \mathrm{Ca}_{x} \mathrm{Fe}_{5-x} \mathrm{Sn}_{x} \mathrm{O}_{12}$ (Lyubutin et al 1967 ) systems.

\section{Conclusion}

The study of $\mathrm{Y}_{3-x} \mathrm{Ca}_{x} \mathrm{Fe}_{5-x} \mathrm{Ti}_{x} \mathrm{O}_{12}$ system has shown that in the range of $0<x<0.7$ the $H_{\text {hf }}$ falls with increase in $x$ in agreement with the observed magnetization data. The QS on the $d$-site is higher than the QS on the $a$-site and the former shows a slight increase 
with increase in $\mathrm{Ti}^{4+}$ substitution. This observation shows that tetragonal sublattice deviates more from the cubic symmetry than the octahedral sublattice and that increase in $\mathrm{Ti}^{4^{+}}$substitution increases the distortion of oxygen tetrahedra on the $d$-site.

\section{References}

Lyubutin I S, Markarov E F and Povitsk V A 1967'Sov. Phys. JETP 2644

Lyubutin I S, Belyaev L M, Vishnyakov Yu S, Dmitrieva T V, Dodokin A P, Dubossarskya V Ya and Shyakhina L P 1970 Sov. Phys. JETP 31647

Om Parakash and Bahadur D 1982 Magnetic and electrical properties of Ti-substituted yttrium iron garnet,

Presented at Third Joint Intermag-Magnetism and Magnetic Materials 